\title{
Why We Don't Come: Patient Perceptions on No-Shows
}

Naomi L. Lacy, $P b D^{1}$

Audrey Paulman, MD, $M M M^{1}$

Matthew D. Reuter, $B A^{2}$

Bruce Lovejoy, MSN, APRN, FNP-C $C^{3}$

'University of Nebraska Medical Center, Department of Family Medicine, Omaha, Neb

${ }^{2}$ University of Nebraska Medical Center, College of Medicine, Omaha, Neb

${ }^{3}$ University Medical Associates Family Practice Clinic at Baker Place, Omaha, Neb

\begin{abstract}
PURPOSE Patients who schedule clinic appointments and fail to keep them have a negative impact on the workflow of a clinic in many ways. This study was conducted to identify the reasons patients in an urban family practice setting give for not keeping scheduled appointments.
\end{abstract}

METHODS Semistructured interviews were conducted with 34 adult patients coming to the clinic for outpatient care. Interviews were audiotaped and transcribed verbatim. A multidisciplinary team used an immersion-crystallization organizing style to analyze the content of the qualitative interviews individually and in team meetings.

RESULTS Participants identified 3 types of issues related to missing appointments without notifying the clinic staff: emotions, perceived disrespect, and not understanding the scheduling system. Although they discussed logistical issues of appointment keeping, participants did not identify these issues as key reasons for nonattendance. Appointment making among these participants was driven by immediate symptoms and a desire for self-care. At the same time, many of these participants experienced anticipatory fear and anxiety about both procedures and bad news. Participants did not feel obligated to keep a scheduled appointment in part because they felt disrespected by the health care system. The effect of this feeling was compounded by participants' lack of understanding of the scheduling system.

CONCLUSIONS The results of this study suggest that reducing no-show rates among patients who sometimes attend might be addressed by reviewing waiting times and participants' perspectives of personal respect.

Ann Fam Med 2004;2:541-545. DOI: 10.1370/afm.123.

\section{INTRODUCTION}

$\mathrm{P}$ atients who schedule clinic appointments and fail to keep them have a negative impact on patient care, productivity, and learning opportunities. ${ }^{1-4}$ The financial impact is not relieved by same-day appointments. ${ }^{1}$ The size of the problem varies, ${ }^{3,5,6}$ but an average of $42 \%$ of appointments become no-shows. ${ }^{7}$

Previous research indicates patients who miss appointments tend to be younger ${ }^{2,8-11}$ and of lower socioeconomic status. ${ }^{2,11}$ They often have a history of failed appointments, ${ }^{2}$ government-provided health benefits, ${ }^{9,10}$ and psychosocial problems. ${ }^{12}$ They are also less likely to understand the purpose of the appointment. ${ }^{8}$ No-show rates increase with increasing time between scheduling and the actual appointment. ${ }^{3,10,11,13}$ Longer waiting times have been shown to be related to lower satisfaction, ${ }^{14,15}$ which, in turn, leads to less reliable appointment keeping. ${ }^{16}$

In addition to forgetting appointments, ${ }_{1}^{11,12}$ patients have provided several reasons for no-shows. Logistical issues include trouble getting off work, ${ }^{8,11}$ child care, ${ }^{11}$ transportation, ${ }^{8,12,13}$ and cost. ${ }^{2,5,13}$ In addition, both patients who felt better ${ }^{2,8,12}$ and patients who felt too unwell to come ${ }^{2,8,12}$ failed to show.

A variety of interventions have been tried, although none has been consistently effective. ${ }^{7,13}$ The most popular $2,6,9,10,13,17,18$ and effective ${ }^{19}$ 
have been reminder calls or mailings. Other methods include providing transportation, ${ }^{9}$ new-patient education, ${ }^{2,7}$ scheduling changes, ${ }^{3,18}$ and incentives or disincentives. ${ }^{13,20}$ In addition, overbooking by expected no-show rates has been recommended. ${ }^{13}$ After interventions, some clinics still have high levels of no-shows. For example, Festinger et $\mathrm{al}^{3}$ report postintervention no-show rates of $28 \%$ to $45 \%$. One third of residency clinics have no-show rates that exceed $20 \%$ despite use of reminder systems. ${ }^{4}$

This literature in the area of appointment keeping does not explain why patients do not telephone to cancel appointments, why patients cancel appointments they made only a few hours earlier, or what causes the portion of no-shows that are unaffected by interventions. The current study resulted from a decision to try to reduce the number of missed appointments at one academic family medicine clinic. This study was designed to answer the question, "What are the reasons patients at this clinic give for failed appointments?"

\section{METHODS}

\section{Study Design and Setting}

We chose a qualitative design to allow broader exploration of issues and to limit the impact of the researchers' preconceptions of the causal basis for failed appointments. The participants were patients at an urban, university-affiliated family practice clinic. The clinic is located in an ethnically diverse neighborhood and serves a predominantly low-income population. Interviews, conducted in the clinic's examination rooms, were tape recorded and later transcribed verbatim.

\section{Subjects}

Participants were selected from sequential patients arriving for outpatient care on selected days in July 2001. As a result, they represent those who were able to overcome attendance barriers at least part of the time. Although a community-based sample would provide a better indication of lack of access, we believed the population selected could better explain no-show rates in those with access. All adult, English-speaking patients were eligible to participate.

The University of Nebraska Medical Center Institutional Review Board provided human subjects approval. Each subject was provided with a description of the study, informed of the right to not participate, and given an alias.

\section{Instruments}

An open-ended interview guide (Table 1) was developed on the basis of extant literature to elicit personal experiences of missed appointments and perceptions of

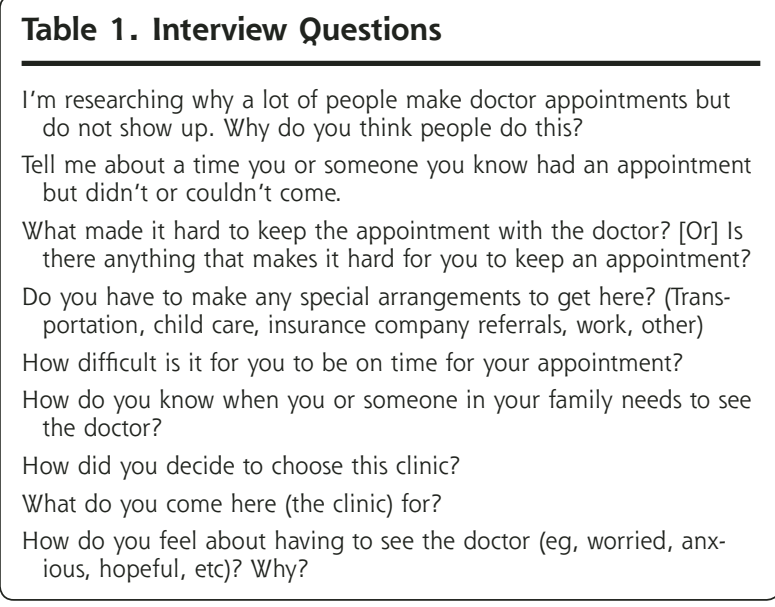

accessing health care. Interviews were kept brief (12 to 15 minutes). An iterative interview and analysis process was used. ${ }^{21}$ Data collection was terminated when we reached saturation. In addition to the interviews, the interviewer conducted retrospective database reviews to determine the participant's past appointment-keeping behavior. We did not request financial information, as the patients attending this clinic were predominantly of low income.

\section{Data Analysis}

The multidisciplinary team used an immersion-crystallization organizing style ${ }^{22}$ to analyze the content of the interviews individually and in team meetings. The team was composed of a family physician (AP), a nurse-practitioner (BL), a medical sociologist (NLL), and a medical student (MDR).

\section{RESULTS}

\section{Overview}

Researchers interviewed 32 women and 2 men. The respondents were all adults, median age 40 years (range, 22 to 78 years). Of the respondents who provided their race (one fourth of the sample chose not to provide this information), 58\% were African American, 37\% were European American, and the remaining 4\% were Hispanic Americans. A review of the patients' histories indicated a median of 4 (range 0 to 22) missed appointments ( 5 had never missed an appointment). All had kept at least 1 other appointment (median 14, range 2 to 76). Three interconnected themes emerged from the interviews as barriers to appointment attendance: emotional barriers, perceived disrespect of the patient's beliefs and time by the health care system, and distrust and lack of understanding of the scheduling system. Transportation and child care were logistical barriers, but respondents noted they could be overcome. 


\section{Emotional Barriers to Keeping Appointments}

Twenty-two participants (65\%) mentioned emotional barriers to keeping appointments. At times, the negative emotions about going to see the doctor were greater than the perceived benefit of keeping the appointment. For some, the delay between the scheduling and keeping of the appointment contributed to this dynamic. Participants described a sense of urgency in scheduling an appointment when illness struck. Participants then described a sense of hesitancy at keeping the scheduled appointment, especially when several days had elapsed between the time of scheduling and the date of the actual appointment.

Although participants discussed scheduling an appointment as a step provoked by a sense of urgency, keeping the appointment was not positively anticipated. Ms. B stated, "Cause the doctor sometimes is really the last person you want to see. You kind of want to keep on going." The participants were hesitant when they were certain they would endure some uncomfortable procedures, such as a pelvic examination, blood draws, shots, or being weighed. For example, Ms. U remembered her feelings regarding an appointment she had missed: "I said, 'Nope, I'm not going! That's uncomfortable'... so I just didn't come." While Ms. U was willing to make the appointment for follow-up care as her doctor had advised, she chose not to keep the appointment because of her negative anticipation of the visit.

Likewise, self-resolving symptoms resulted in missed appointments. Ms. Y explained, "If it isn't a dire need to get into the doctor's office ..., then people forget about it.... My feet swelling, when they're swollen it was on my mind, but as soon as the swelling went down, then I forgot about it."

Fear was another barrier. Ms. H's response typified fear of the unknown: "I just don't want to go to the doctor. I'm scared they might tell you something, some bad news.... Come in with a headache and they say you've got a big brain tumor up there...." Ms. J's response typified fear of receiving bad news: "Because ... I don't want to go back... I don't want to hear no bad news."

\section{Perceived Disrespect of the Patients' Beliefs and Time by the Health Care System}

Fifteen participants (44\%) commented on issues of respect by the health care system. From their viewpoints, health care staff did not respect patients, discounting patients' time, opinions, and feelings.

Waiting was one way disrespect was communicated: the patients' wait to get an appointment time, the patients' wait in the waiting room, and the patients' wait in the examination room. Ms. E explained, "Part of it, too, may be that there's so many appointments scheduled ... that it, it's just an assembly line thing.... People want to be treated like human beings. They don't wanna be cattle just running in the lounge."

Sometimes patients also felt the health care staff did not respect their history, especially if the symptoms had resolved by the time of the visit. Ms. G: "I have to wait so long and then my pain is gone and I come here and they're like, 'I can't see anything. We can't find nothing."'

Some participants also felt the providers and insurance companies did not respect their opinions. Ms. V said, "You have to call your family doctor to get a refer$\mathrm{ral}_{i} \ldots$ it pisses me off something fierce, 'cause if I need to go to somebody else, I don't need my doctor to tell me I need to go there." Discussing a conflicting viewpoint with her doctor, Ms. V added, "Well they're telling me I need it (surgery) and I'm telling them I don't. After seeing what happened to my friend, you've got to be out of your brains."

\section{Lack of Understanding of the Scheduling System}

Forty-one percent of the participants indicated they did not know what happens in a clinic if there is a failed appointment. Ms. S speculated, "Maybe they just go to the next patient." Participants seemed unaware of the financial impact of a failed appointment and believed a no-show may actually be a positive event for the clinician and staff. When asked what the staff and clinician do if someone does not show for a scheduled appointment, Ms. H stated: "I don't know. I guess they get free time." Similarly, Ms. B said: "You know what, I don't know. I know that if it's a crowded day, they're probably very happy."

According to participants, the appointment schedule is fluid and subject to negotiation. Participants believed canceled appointments occur regularly. As a result, they called to schedule an appointment with the hope that they could squeeze into one of these recently vacated spots. As Ms. C explained, "at the clinic there's an opening that nobody knows about..." Participants also failed to understand the triage system. When they got appointments through the nurse, "it kind of irked my nerves" (Ms. Z).

\section{Evaluation of Previously Described Barriers} Consistent with published findings on no-shows, 7 of the respondents blamed transportation problems ( 3 indicated that these were one-time events) for their missed appointment. Only 3 participants identified child care as an issue.

\section{DISCUSSION}

Our results suggest that the process of making and keeping clinic appointments is multifactorial rather than the result of a single decision. Imagine the following scenario: 
You have had a pain in your stomach and you call the clinic for an appointment. The only available appointment is in 5 days; you feel the clinic staff are not treating your concern seriously, but take the appointment because you want to take care of yourself. You begin to worry that the pain means you have cancer. Then you start to worry about what kinds of tests the doctor is going to perform; you are sure any tests will be uncomfortable and worry they might involve needles. As time goes by, you become increasingly worried. Finally you convince yourself that the symptoms are not getting worse, so it must not be serious; you decide not to keep your appointment. You do not bother to telephone and tell the clinic because they are so busy they will not even notice your absence, although it might give the doctor 10 minutes to catch up on his work (because he always seems to be behind).

This scenario summarizes our participants' explanations for not showing up for appointments: inability to get an appointment right away, anxiety or fear about the cause of the symptoms and anticipated diagnostic tests, feeling disrespected, symptoms improving (or not getting worse), and lack of understanding of the scheduling system. In this scenario, although transportation or child care problems might contribute to no-shows, they were not primary causes of no-shows. ${ }^{23}$

Our participants' discussions create a much richer and more complex understanding of the issues involved in not keeping appointments. They emphasize the personal meanings of their symptoms, resulting emotions, and anticipated consequences, along with their perceived relationship with and trust in the clinic staff. Conceptually, keeping a clinic appointment is the result of a combination of these factors.

Issues of respect could explain why patients do not telephone to cancel. The norm of reciprocity sug gests that a patient who feels disrespected would feel no obligation to respect the system. Our results suggest the intriguing possibility that a single construct, respect, underlies the association of waiting, satisfaction, and nonattendance. ${ }^{14,15}$ Such an association would be consistent with the observation by Sharp et al that overbooking based on expected no-show rates is counterproductive, ${ }^{11}$ as overbooking increases in-clinic waiting times.

Interventions, such as open access scheduling systems, that decrease the delay between scheduling and appointment $t^{15,24,25}$ should effectively address no-shows caused by fear. The implications of our results for open access are both positive and negative. Such systems eliminate the time delay that causes increasing anxiety and fear. On the other hand, waiting in the clinic was a factor in the "cattle running in the lounge" dimension of respect. As patients spend increasing amounts of time waiting in the clinic, there is a potential that they will feel greater amounts of disrespect. To address this issue, open access clinic staff may need to explain very clearly to patients that they can be seen today but may have to wait for a substantial length of time.

Our results also raise questions about the delivery of care to patients who are afraid of what might happen during an appointment. For those patients, fear may explain the higher rate of no-shows in followup appointments, ${ }^{8}$ particularly if symptoms begin to resolve. If providers inquire about a patient's fears, they might identify which patients are likely to not keep their appointments. These patients might benefit from targeted messages explaining what to expect and why it will be important.

The qualitative design of this study allowed for an in-depth exploration of the perceived barriers experienced by patients receiving care in an urban clinic. Rather than looking for issues that might apply to a greater number of clinic patients, we obtained detailed descriptions of the experiences of a few patients so we could gain a deeper understanding of no-show behavior and generate hypotheses for future research.

The area of appointment keeping deserves further research. The interrelation of fear, respect, and appointment keeping, in particular, provides a potentially rich foundation for developing new interventions.

To read or post commentaries in response to this article, see it online at http://www.annfammed.org/cgi/content/full/2/6/541.

Key words: Office visits, no-shows; patient satisfaction; patient compliance; attendance; family practice

Submitted October 31, 2002; submitted, revised, December 19, 2003; accepted January 12, 2004.

An earlier version of this article was presented at the Society for Teachers of Family Medicine annual spring conference 2002, April 27 - May 1, 2002, San Francisco, Calif.

Funding support: Funding for research provided by University of Nebraska Medical Center, College of Medicine.

\section{References}

1. Moore CG, Wilson-Witherspoon P, Probst JC. Time and money: effects of no-shows at a family practice residency clinic. Fam Med. 2001;33:522-527.

2. Barron WM. Failed appointments. Who misses them, why they are missed, and what can be done. Prim Care. 1980;7:563-574.

3. Festinger DS, Lamb RJ, Marlowe DB, Kirby KC. From telephone to office: intake attendance as a function of appointment delay. Addict Behav. 2002;27:131-137.

4. Hixon AL, Chapman RW, Nuovo J. Failure to keep clinic appointments: implications for residency education and productivity. Fam Med. 1999;31:627-630. 
5. Mirotznik J, Ginzler E, Zagon G, Baptiste A. Using the health belief model to explain clinic appointment-keeping for the management of a chronic disease condition. J Community Health. 1998;23:195-210

6. O'Brien G, Lazebnik R. Telephone call reminders and attendance in an adolescent clinic. Pediatrics. 1998;101:e6.

7. Macharia WM, Leon G, Roewe BH, Stephenson BJ, Haynes RB. An overview of interventions to improve compliance with appointment keeping for medical services. JAMA. 1992;267:1813-1817.

8. Frankel S, Farrow A, West R. Non-attendance or non-invitation? A case-control study of failed outpatient appointments. BMJ. 1989;298:1343-1345.

9. Smith CM, Yawn BP. Factors associated with appointment keeping in a family practice residency clinic. J Fam Pract. 1994;38:25-29.

10. Moser SE. Effectiveness of post card appointment reminders. Fam Pract Res J. 1994;14:281-288.

11. Sharp DJ, Hamilton W. Non-attendance at general practices and outpatient clinics. BMJ. 2001;323:1081-1082.

12. Cosgrove MP. Defaulters in general practice: reasons for default and patterns of attendance. Brit J Gen Pract. 1990;40:50-52.

13. Bean AG, Talaga J. Appointment breaking: causes and solutions. J Health Care Marketing. 1992;12:14-25.

14. Bower P, Roland M, Campbell J, Mead N. Setting standards based on patients' views on access and continuity: secondary analysis of data from the general practice assessment survey. BMJ. 2003;326:258

15. Bar-dayan Y, Leiba A, Weiss Y, Carroll JS, Benedek P. Waiting time is a major predictor of patient satisfaction in a primary military clinic. Milit Med. 2002;167:842-845.
16. Rao JK, Weinberger M, Kroenke K. Visit-specific expectations and patient-centered outcomes: a literature review. Arch Fam Med. 2000;9:1148-1155.

17. Hardy KJ, O’Brien SV, Furlong NJ. Information given to patients before appointments and its effect on non-attendance rate. BMJ. 2001;323:1298-1300.

18. Gatrad AR. A completed audit to reduce hospital outpatients nonattendance rates. Arch Dis Childhood. 2000;82:59-61.

19. Macharia WM, Leon G, Rowe BH, Stephenson BJ, Haynes RB. An overview of interventions to improve compliance with appointment keeping for medical services. J Am Med Assoc. 1992;267:1813-1817.

20. Smoller JW, McLean RY, Otto MW, Pollack MH. How do clinicians respond to patients who miss appointments? J Clin Psych. 1998;59:330-338; quiz 339-340.

21. Huberman AM, Miles MB. Data management and analysis methods. In: Denzin NK, Lincoln YS, eds. Handbook of Qualitative Research. Thousand Oaks, Calif: Sage Publications; 1994:428-444.

22. Borkan J. Chapter 10: Immersion/Crystallization. In: Crabtree BF Miller WL, eds. Doing Qualitative Research. 2nd ed. Thousand Oaks, Calif: Sage Publications; 1999:406.

23. Miller SM, Siejak KK, Schroeder CM, Lerman C, Hernandez E, Helm CW. Enhancing adherence following abnormal pap smears among low-income minority women: a preventative telephone counseling strategy. J Natl Cancer Inst. 1997;89:703-708.

24. Murray M, Berwick DM. Advanced access: reducing waiting and delays in primary care. J Am Med Assoc. 2003;289:1035-1040.

25. Murray M, Bodenheimer T, Rittenhouse D, Grumbach K. Improving timely access to primary care: case studies of the advanced access model. J Am Med Assoc. 2003;289:1042-1046. 